\title{
SISTEM INFORMASI MONITORING PEMBAYARAN PAJAK (SIMPEJAK) PADA KANTOR PELAYANAN PAJAK PRATAMA SUKABUMI
}

\author{
Fidella Risyanli ${ }^{1}$, Denny Pribadi ${ }^{2}$, Saeful Bahri ${ }^{3}$ \\ 1,2 Universitas Bina Sarana Informatika \\ e-mail: haqqiu.95@gmail.com, denny.dpi@bsi.ac.id \\ ${ }^{3}$ STMIK Nusa Mandiri \\ e-mail: saeful.sel@nusamandiri.ac.id
}

\begin{abstract}
Abstrak
Sebagai instansi pemerintah yang bertugas melaksanakan penyuluhan, pelayanan, dan pengawasan Wajib Pajak, salah satu fungsi Kantor Pelayanan Pajak Pratama (KPP) adalah pengumpulan, pencarian dan pengolahan data, pengamatan potensi perpajakan, penyajian informasi perpajakan, serta pendataan objek dan subjek. Dalam pelaksanaan tugas dan fungsi tersebut, perlu adanya perbaikan sistem dalam hal rekapitulasi data Wajib Pajak Tidak Lapor Tidak Bayar (WP TLTB). Pengawas atau Account Representative (AR) harus mengakses terlebih dahulu website terpadu pajak dan mencari data wajib pajak satu-persatu pada saat pemberian himbauan kepada WP TLTB. Penelitian ini menggunakan metode Software Development Life Cycle (SDLC) model Prototype untuk mempersingkat waktu pengembangan sistem informasi. Dengan adanya sistem informasi ini AR tidak perlu susah payah untuk merekap satu-persatu data wajib pajak yang akan diberi himbauan atau di-visit. Form WP TLTB, data WP, data AR, dan data penerimaan pembayaran dapat dilihat secara efektif dan efisien di web SIMPEJAK, sistem informasi ini juga dirancang untuk melakukan rekapitulasi secara otomatis data WP TLTB (Wajib Pajak Tidak Lapor Tidak Bayar) sekaligus dapat mencetak surat himbauan secara otomatis.
\end{abstract}

\section{Kata Kunci: Pajak, Wajib Pajak, Sistem Informasi}

\begin{abstract}
As a government agency tasked with carrying out counseling, services, and supervision of taxpayers, one of the functions of the Primary Tax Service Office (KPP) is collecting, searching and processing data, observing potential taxation, presenting tax information, and collecting data on objects and subjects. In carrying out these tasks and functions, it is necessary to improve the system in terms of recapitulation of taxpayer data not report non-payment (WP TLTB). The Account Representative (AR) must first access the integrated tax website and search for taxpayer data one by one at the time of giving an appeal to the WP TLTB. This study uses the Software Development Life Cycle (SDLC) method of the Prototype model to shorten the time to develop information systems. With the existence of this information system AR does not need to struggle to recapitulate the taxpayer data one by one which will be given an appeal or visit. The WP TLTB form, WP data, AR data, and payment receipt data can be seen effectively and efficiently on the SIMPEJAK website, this information system is also designed to automatically recapitulate WP TLTB data (Taxpayers Not Reporting Not Pay) as well as printing an appeal letter automatically.
\end{abstract}

Keywords: Taxes, Taxpayers, Information Systems 


\section{Pendahuluan}

Diperkirakan, tahun 2018 kemarin total wajib pajak yang terdaftar di Indonesia baru mencapai 38 juta orang. Kemudian, yang melaporkan pendapatan tahunannya (SPT) di tahun 2018 hanya berkisar di angka 17 juta orang. Hingga Oktober 2018, pendapatan Indonesia dari pajak hanya mendapat 1.061 trilyun rupiah. Angka tersebut terbilang cukup kecil untuk membangun berbagai fasilitas dari Sabang sampai Merauke. Nampaknya kesadaran harus bayar pajak di Indonesia Kota Sukabumi di berbagai bidang tersebut maka dengan sendirinya akan menimbulkan berbagai masalah lingkungan sebagai ekses perkembangan kota yang cukup pesat. Berbagai dampak lingkungan yang ditimbulkan antara lain meningkatnya volume sampah yang dihasilkan dari sampah rumah tangga dan sampah pasar yang mana setiap hari produk sampah dari masyarakat rata-rata sekitar 165 ton (Antaranews.com, 2018), tidak terealisasinya Ruang Terbuka Hijau (RTH) secara integrasi yakni 30 persen luas kota (RTH) publiknya 20 persen, dan (RTH) privatnya 10 persen (Pojokjabar.com, 2017), RTH yang semakin berkurang dan kebutuhan lahan pemakaman yang semakin luas, sehingga aspek-aspek tersebut memerlukan penanganan yang serius dari DLH Kota Sukabumi.

Untuk meningkatkan kualitas pelayanan terhadap masyarakat Kota Sukabumi, maka seluruh pegawai DLH Kota Sukabumi dituntut untuk meningkatkan kemampuan yang dimilikinya agar tercapai kinerja yang lebih baik, sebab apabila pegawai DLH Kota Sukabumi memiliki kemampuan yang baik, maka dengan sendirinya pelayanan terhadap masyarakat Kota Sukabumi oleh DLH juga akan lebih baik.

Manusia sebagai unsur utama dalam tercapainya tujuan suatu entitas, sudah barang tentu dituntut memiliki kemampuan, keterampilan, ketekunan dan motivasi yang baik yang dibutuhkan dalam menyelesaikan tugas yang diberikan kepadanya. Untuk mencapai hasil yang optimal dalam memberikan pelayanan kepada masyarakat, sudah seharusnya semua entitas pemerintahan harus menempatkan pegawai sesuai dengan kemampuannya agar tercapainya pelayanan yang maksimal kepada masyarakat.

Masalah yang dihadapi oleh DLH Kota Sukabumi dalam upaya meningkatkan kinerja pegawainya diantaranya adalah menempatkan pegawai yang tidak sesuai dengan kemampuan atau latar belakang pendidikan. Kondisi ini menyebabkan kinerja pegawai DLH yang tidak optimal bahkan dapat dikatakan cederung agak menurun, hal ini dapat dilihat dari berbagai aspek menurunnya hasil kinerja pegawai pada DLH yang tertera pada tabel berikut:

masih belum tinggi. Padahal, demi membangun berbagai fasilitas, pemerintah membutuhkan banyak pemasukan. Salah satu pemasukan terbesar adalah dari pajak (Dhimas, 2019). Pajak memiliki peranan yang signifikan dalam kehidupan bernegara, khususnya pembangunan. Pajak merupakan sumber pendapatan negara dalam membiayai seluruh pengeluaran yang dibutuhkan, termasuk pengeluaran untuk pembangunan.

Pajak dikatakan sebagai iuran wajib masyarakat kepada kas negara. Pajak bisa dipaksakan karena diatur dengan hukum dan tidak mendapatkan kontraprestasi secara langsung kepada perorangan melainkan kontribusinya akan dirasakan oleh seluruh masyarakat (Sugiharti, Suhadak, \& Dewantara, 2015). Menurut Jannah dalam (Sugiharti et al., 2015) "Sumber penerimaan negara terbesar sejauh ini adalah dari sektor pajak. Sektor pajak memberikan sumbangsih hampir $80 \%$ dari total penerimaan negara dilihat dari realisasi penerimaan negara sejak tahun 2010 sampai dengan tahun 2014". Oleh karena itu pembayaran pajak merupakan sesuatu hal yang wajib dan sangat mempengaruhi berkembangnya suatu negara yang nantinya akan menjadi public saving untuk membiayai kebutuhan publik.

Saat ini lebih dari 300.000 Wajib Pajak (WP) terdaftar di Kantor Pelayanan Pajak Pratama (KPP) Sukabumi dan ada sekitar 30.000 usahawan maupun badan terdaftar dan tercatat aktif beroperasi. Data tersebut hanya bisa dilihat oleh petugas KPP Pratama Sukabumi. Permasalahan timbul saat jumlah petugas Pengawas atau Account Representative (AR) KPP Pratama Sukabumi yang bertanggung jawab menangani seluruh wajib pajak di Sukabumi tidak memadai. Jumlah pengawas tidak sebanding dengan jumlah wajib pajak khususnya untuk usahawan dan badan, sehingga pengawas membutuhkan tenaga ekstra untuk memonitoring maupun menangani wajib pajak yang belum melakukan pembayaran demi tercapainya target penerimaan kas negara.

Data wajib pajak bisa dilihat di SIDJP (Sistem Informasi Direktorat Jendral Pajak) berupa data perorangan ataupun data per badan, pengawas harus melihat satu persatu 
NPWP wajib pajak di website SIDJP dengan kondisi website tersebut berbasis intranet dimana hanya bisa di akses di kantor pajak. Pengawas harus membuka satu persatu data untuk melihat wajib pajak sudah melakukan pembayaran pajak atau belum. Hal ini cukup menyulitkan khususnya bagi bagian pengawasan untuk mengetahui wajib pajak mana saja yang belum melakukan pembayaran dan harus diberikan himbauan ataupun dikunjungi.

Berdasarkan hal tersebut maka perlu dibangun suatu sistem untuk mengetahui data pendaftar NPWP setiap bulan dan informasi penerimaan pembayaran pajak di bulan tersebut yang berbasis internet agar dapat diakses dengan mudah oleh pengawas dimana saja dan kapan saja.

\section{Metode Penelitian}

\section{A. Metode Pengembangan Perangkat} Lunak

Model Prototype merupakan salah satu model dari SDLC (Software Development Life Cycle), dalam penelitian in digunakan Model Prototype yang terbagi menjadi tiga tahapan:

1. Mengumpulkan Kebutuhan Pengguna Proses pengumpulan data dilakukan dengan cara menganalisa data, mempelajari kebutuhan pengguna, dan mempelajari sistem yang berjalan, serta mengidentifikasi permasalahan yang terjadi di KPP Pratama Sukabumi.

2. Membangun atau Memperbaiki Prototype Setelah mengumpulkan kebutuhan pengguna, dilakukan pembangunan prototype atau perangkat lunak berupa rancangan sistem dengan memperbaiki sistem yang ada atau memperbaharui sistem yang ada di KPP Pratama Sukabumi.

3. Melihat atau Menguji Prototype

Tahap ini merupakan tahapan nyata pembuatan suatu sistem. Hal ini mengartikan bahwa sistem yang sebenarnya telah siap untuk dibuat setelah dilakukannya pembuatan kerangka sistem. Setelah perancangan perangkat lunak selesai, maka dilakukan pengujian terhadap sistem yang telah dibuat perangkat lunak.

\section{B. Teknik Pengumpulan Data}

1. Observasi

Dilakukan dengan cara menganalisis dan mengadakan pencatatan secara sistematis mengenai hal-hal yang berkaitan dengan masalah yang diteliti secara langsung.
Adapun sumber data yang diperlukan berasal dari Kantor Pelayanan Pajak Pratama Sukabumi.

2. Wawancara

Untuk mendapatkan informasi secara lengkap maka dikumpulkan data dengan cara bertanya dan berdialog langsung dengan Kepala Seksi Pusat Data dan Informasi dan Pelaksana Seksi Pusat Data dan Informasi Kantor Pelayanan Pajak Pratama Sukabumi.

3. Studi Pustaka

Melakukan pengumpulan data dengan cara membaca, meneliti dan menganalisis bukubuku dan referensi lain yang berhubungan dengan masalah penelitian ini.

\section{Hasil dan Pembahasan}

3.1. Analisis Kebutuhan

A. Kebutuhan Pengguna

Dalam aplikasi Sistem Informasi Monitoring Pembayaran Pajak berbasis website ini terdapat dua pengguna yang saling berinteraksi yaitu bagian Pusat Data dan Informasi sebagai administrator dan Pengawas atau AR sebagai user.

A1. Kebutuhan Bagian Pusat Data dan Informasi

a) Mengelola data AR.

b) Mengelola data WP.

c) Mengontrol database dari SIDJP ke aplikasi.

A2. Kebutuhan bagian AR

a) Mengolah data WP.

b) Dapat melihat data WP yang sudah bayar.

c) Melihat data target pencapaian pembayaran dan yang sudah dicapai.

d) Mencetak surat himbauan WP.

B. Kebutuhan Sistem

1) Sistem melakukan rekapitulasi data pembayar pajak di bulan tersebut.

2) Mengolah data target pencapaian pembayaran yang sudah maupun belum dicapai setiap AR.

3) Pengguna baik AR maupun administrator harus melakukan login saat masuk ke aplikasi dan logout jika selesai menggunakan aplikasi.

\subsection{Use Case Diagram}


JURNAL SWABUMI, Vol. 7 No. 1 Maret 2019, pp. 77 83

ISSN: 2355-990X

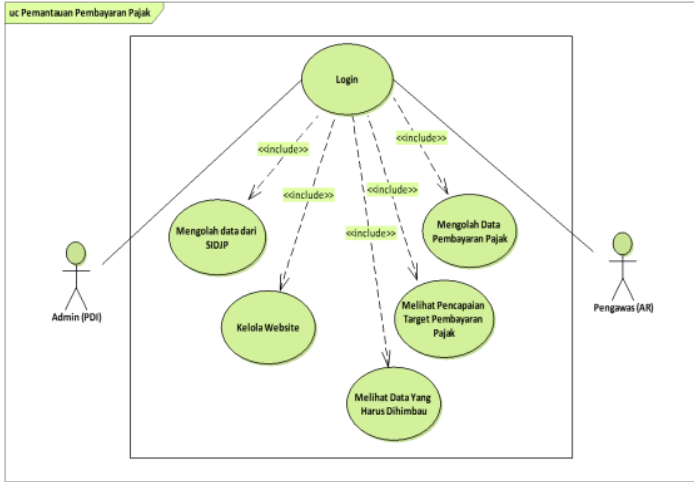

Gambar 1. Use Case Diagram

\subsection{Activity Diagram}

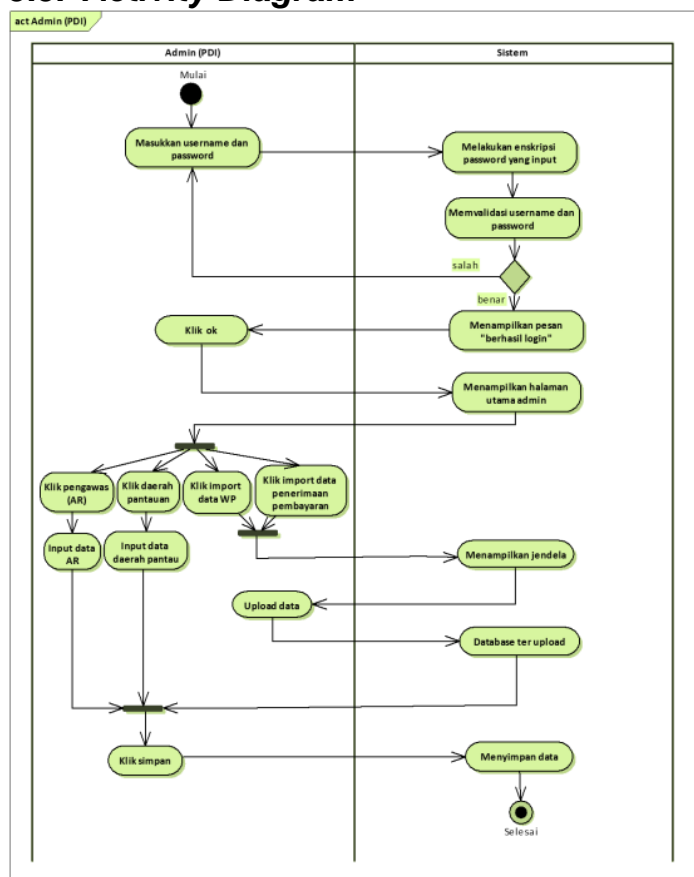

Gambar 2. Activity Diagram Administrator (Pusat Data dan Informasi)

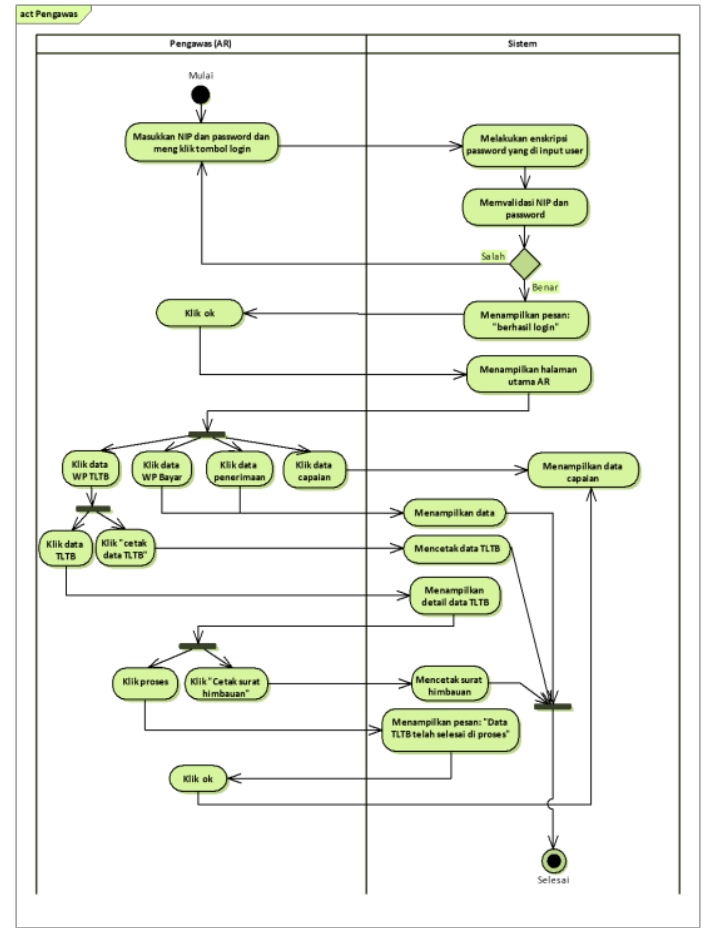

Gambar 3. Activity Diagram Pengawas (Account Representative)

\subsection{Entity Relationship Diagram (ERD)}

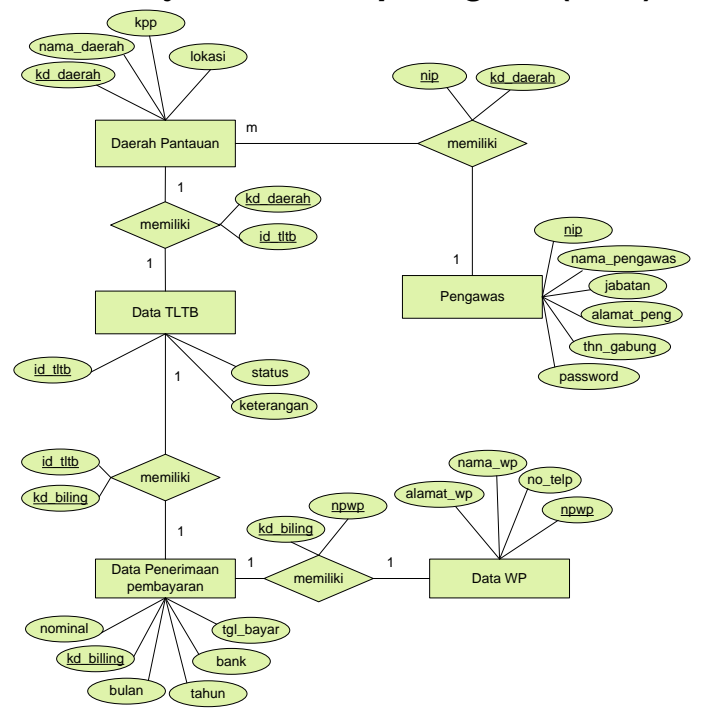

Gambar 4. Entity Relationship Diagram

3.5. Logical Structure Record (LRS) 


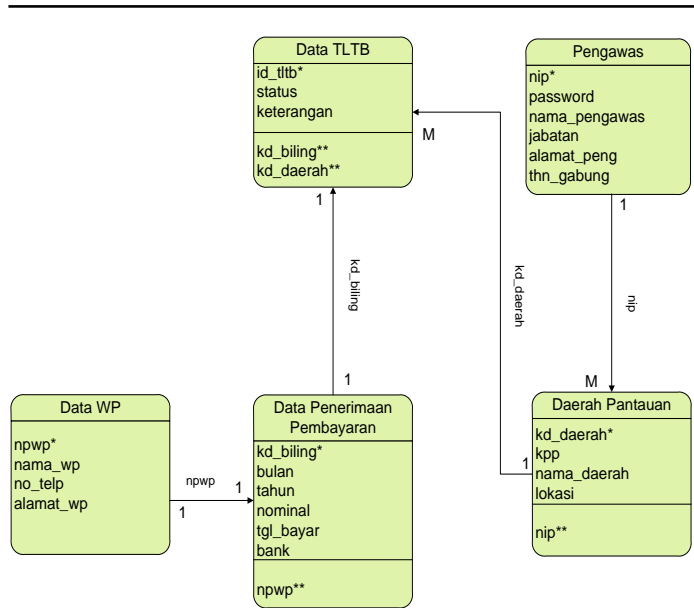

Gambar 5. Logical Structure Record

\subsection{Class Model/Class Diagram}

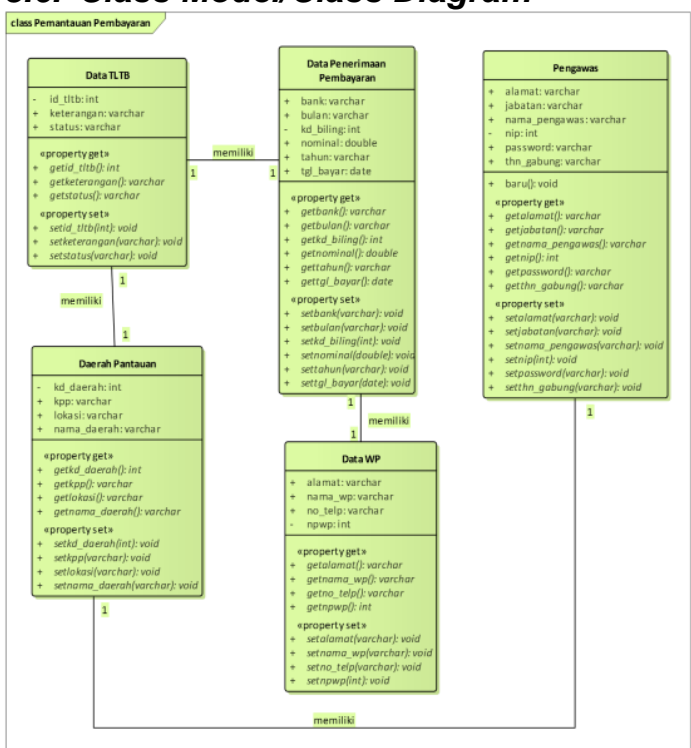

Gambar 6. Class Diagram

\subsection{Sequence Diagram}

a. Sequence Diagram Penerimaan Pembayaran

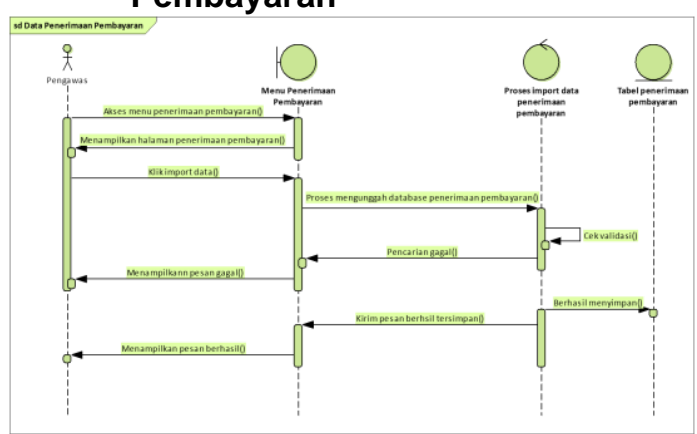

Gambar 7. Sequence Diagram

Penerimaan Pembayaran b. Sequence Diagram Data TLTB (Tidak Lapor Tidak Bayar)

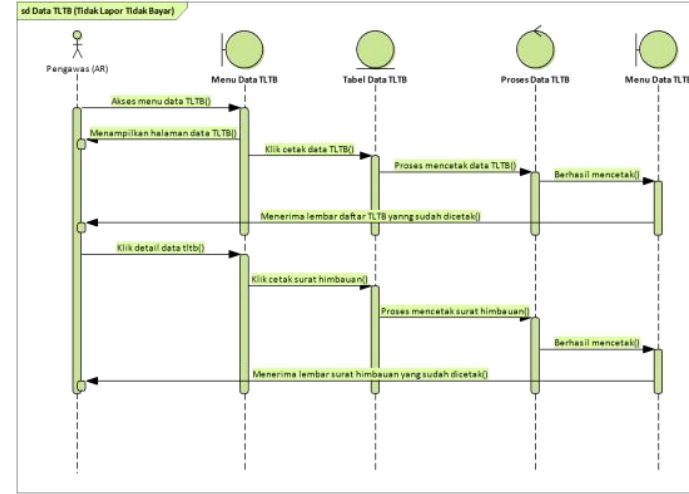

Gambar 8. Sequence Diagram Data TLTB (Tidak Lapor Tidak Bayar)

\subsection{Implementasi}

a. Form Wajib Pajak

Halaman ini berfungsi untuk import database WP dari SIDJP ke website SIMPEJAK.

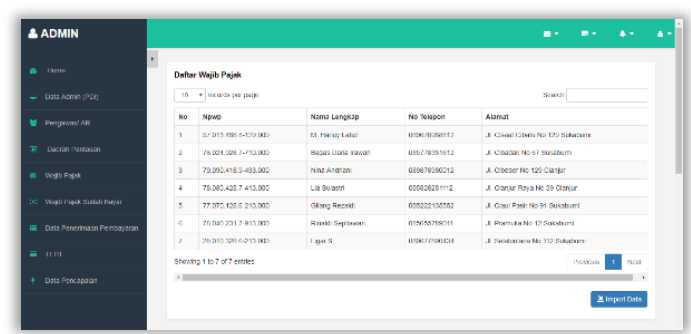

Gambar 9. Form Wajib Pajak

b. Form Wajib Pajak Sudah Bayar Halaman ini berisi data WP yang sudah melakukan pembayaran.

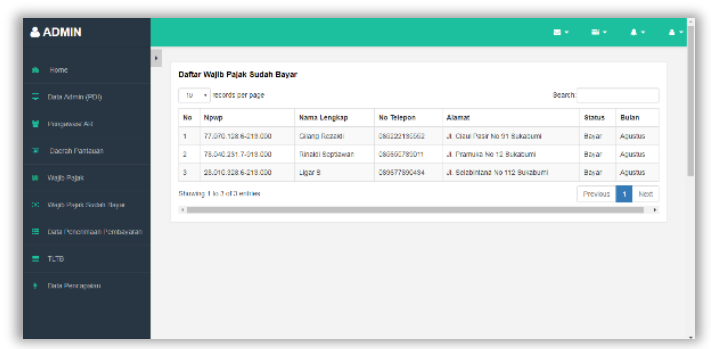

Gambar 10. Form Wajib Pajak Sudah Bayar

c. Form Penerimaan Pembayaran Halaman ini berfungsi untuk import database penerimaan pembayaran dari SIDJP ke website SIMPEJAK. 

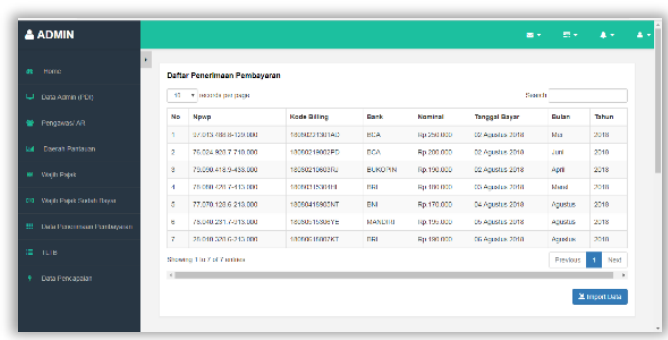

Gambar 11. Form Penerimaan Pembayaran Pajak

\section{d. Form TLTB (Tidak Lapor Tidak} Bayar)

Halaman ini berisi daftar WP TLTB yang sudah terekap oleh sistem.

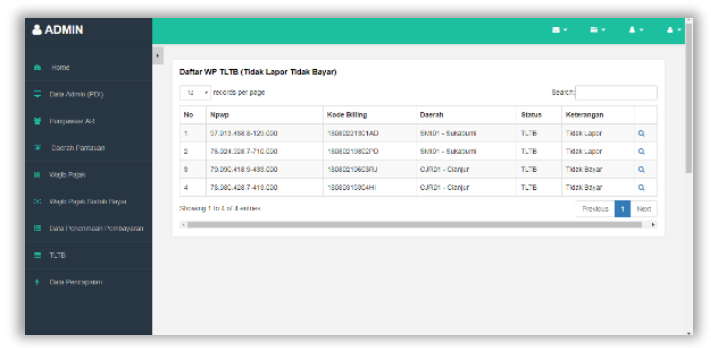

Gambar 12. Form TLTB

e. Form Data Capaian

Halaman ini menampilkan data capaian pembayaran pajak yang telah dicapai oleh AR.

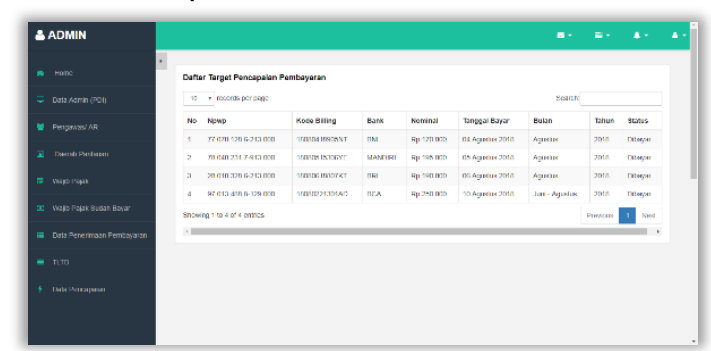

Gambar 13. Form Data Capaian

\section{f. Form Data WP}

Halaman ini berisikan data WP yang dapat di akses oleh AR.

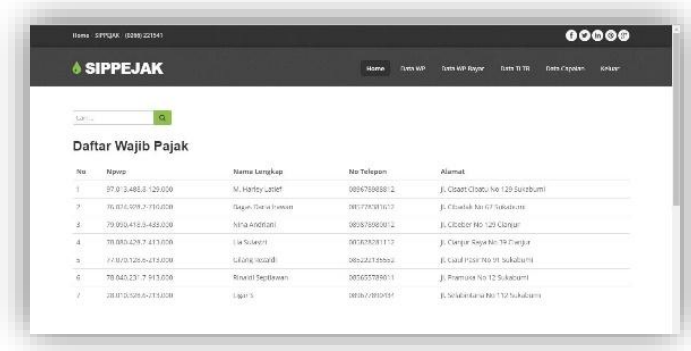

Gambar 14. Form Data WP

\section{g. Lembar Cetak Data TLTB} (Dokumen Keluaran) Lembar data TLTB yang sudah dicetak.

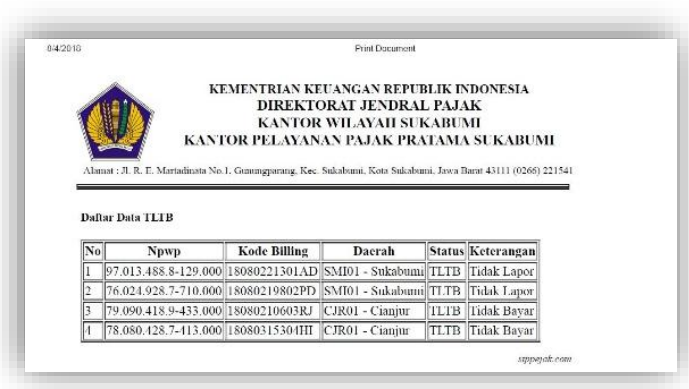

Gambar 15. Lembar Cetak Data TLTB (Dokumen Keluaran)

\section{h. Form Detail Data TLTB}

Halaman ini berfungsi untuk menampilkan detail data WP TLTB.

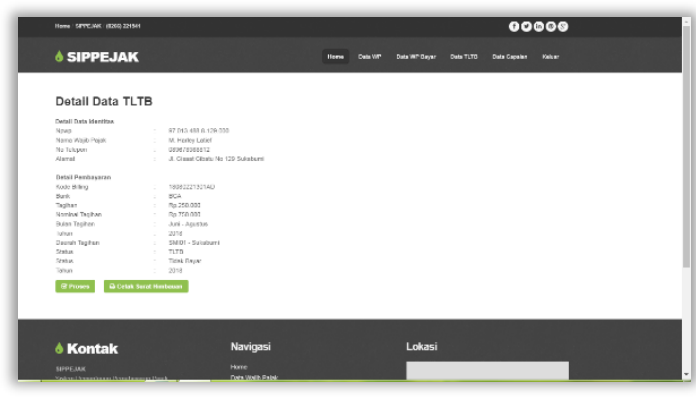

Gambar 16. Form Detail Data WP TLTB (AR)

\section{i. Form Data Capaian}

Halaman ini berisi daftar data capaian yang dapat diakses oleh AR

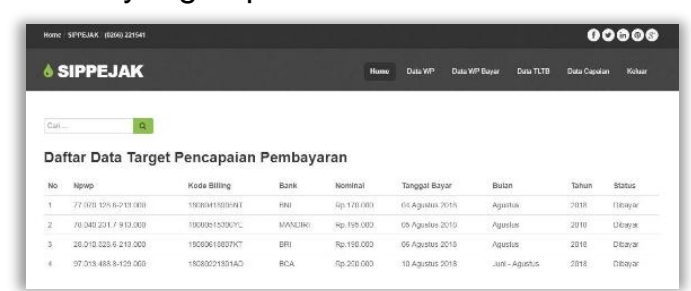

Gambar 17. Form Data Capaian

\section{Kesimpulan}

1. Sistem Informasi Monitoring Pembayaran Pajak (SIMPEJAK) dirancang untuk dapat melakukan rekapitulasi data WP TLTB (Wajib Pajak Tidak Lapor Tidak Bayar) dan mencetak surat himbauan secara otomatis.

2. Dengan adanya SIMPEJAK, pengawas atau AR tidak harus ke kantor untuk mendapatkan secara detail data WP yang harus dihimbau atau di visit.

3. SIMPEJAK diharapkan dapat membantu pengawas atau AR dalam memenuhi 
JURNAL SWABUMI, Vol. 7 No.1 Maret 2019, pp. 77 83

ISSN: 2355-990X

target pencapaian pembayaran pajak

setiap tahunnya khususnya di Sukabumi.

\section{Referensi}

Dhimas. (2019). Harus Bayar Pajak, Apa Pentingnya? Diambil dari https://www.domainesia.com/berita/haru s-bayar-pajak/

Jogiyanto. (2014). Analisa dan Desain. Yogyakarta: ANDIOFFSET.

Muhamad Muslihudin, O. (2016). Analisis dan Perancangan Sistem Informasi Menggunakan Model Terstruktur dan UML. (A. Pramesta, Ed.) (Vol. 118). Yogyakarta: ANDIOFFSET.

Mulyani, S. (2017). Metode Analisis dan Perancangan Sistem (2 ed.). Bandung: ABDI SISTEMATIKA. Diambil dari https://bit.ly/2E3COsD

Priyadi, Y. (2014). Kolaborasi SQL \& ERD dalam implementasi Database. (Maya, Ed.). ANDIOFFSET.

Sugiharti, M. A., Suhadak, \& Dewantara, R. Y. (2015). Analisis Efektivitas dan Kelayakan Sistem Pelaporan Pajak Menggunakan E-Filing Terhadap Kepuasana Wajib Pajak (Studi Pada KPP Pratama Malang Utara Periode 2015). Jurnal Perpajakan (JEJAK), 6(2), $1-10$. 